The event has certainly justified their instincts, for until to. day, January $\mathbf{I}$, it has been almost impossible for the birds to obtain any food, except from the berries, which this year are exceptionally plentiful.

Large flocks of fieldfares have taken possession of my garden, where there are a great many hollies, and at any noise they rush out of the bushes like a swarm of flies. It is curious to watch them from the windows in the morning, some ten or a dozen sitting in the snow under the bushes, mere dejected heaps of feathers, occasionally pecking at the berries that their busy comrades have knocked off. The thrushes are in the wildest excitement. They sit above the hollies, quivering and chattering, and occasionally darting upon a luckless fieldfare, whose unwonted presence they resent most strongly. I do not know how these birds discover the berries. It cannot be by their colour, for there are two large hollies within ten yards of each other; one of them was for days full of birds constantly flying past the other, which was almost a mass of brilliant red berries. One tree was almost stripped bare, and the birds all went to an adjoining field for three days. Then one morning I found them in the remaining bush, which they speedily stripped as bare as the rest.

Throwleigh Rectory, Devon, January $x$.

E. C. SPICER.

\section{On the Flight of Oceanic Birds.}

THE oceanic soaring birds undoubtedly take advantage of the air-currents as sailing-vessels do, trimming their wings so as to be acted on by the wind to the best advantage. I have frequently observed their flight in high southern latitudes, and have seen the sooty albatross sail round, and up and down, for ten minutes and more with never a flap of the wings ; but with a pair of binoculars the tail, head, and portions of the wings could be seen to move slightly with each change of direction or elevation.

There are two well-marked ways of flying, as follows: $(a)$ when the bird is flying with the wind blowing sideways on to it, as represented in Fig. $\mathbf{I}$, where it will be seen the whole of the
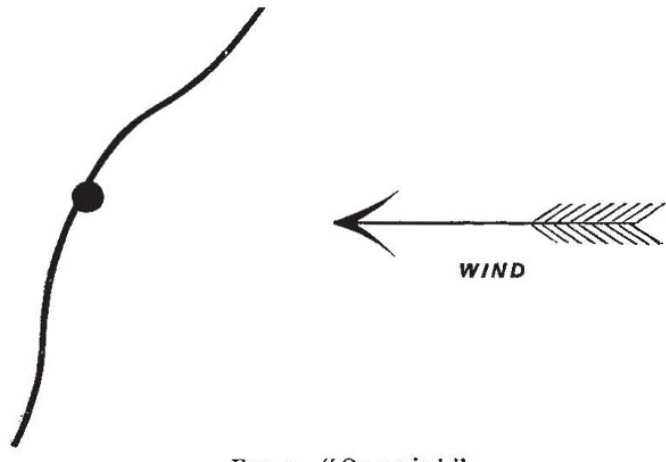

Fig. x.-"On a wind."

under surface is exposed to the wind; and $(b)$ when the bird is flying either directly towards or from the direction of the wind, as in Fig. 2, in this position a slight movement of the tail sending the bird up or down, and of the wings (not a flap) altering the direction.

Roughly speaking, the area of wing surface exposed to the wind is about 3 square feet, and the weight of the bird 7 pounds (sooty albatross). In all these true oceanic birds the wings are long and narrow, and the birds appear to have great power over the movements of the different joints.

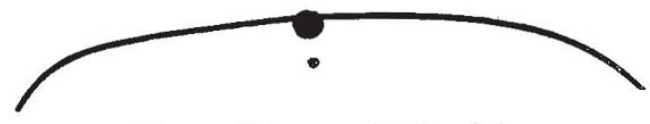

FiG. 2,-Before or against the wind.

In calm weather the birds constantly settle on the water, and when flying flap their wings a good deal. As the wind makes and increases, the flaps become less in number, until the birds sweep round and under the stern of the ship in immense circles at the rate of 20 to 30 miles per hour, in most cases as represented in Fig. 3, at the part marked $(a)$ close to the sea surface, and at $(b)$ high in the air.

It is a common thing in high winds to see them apparently motionless for some time over the mast-heads, the ship at the same time going through the water at a speed of Io or I I knots per hour.

I would not pretend in any way to explain their marvellous fight, but one thing should be remembered, that the velocity of the air certainly increases from the surface of the sea to the altitude to which they attain, viz. about 200 feet; and that
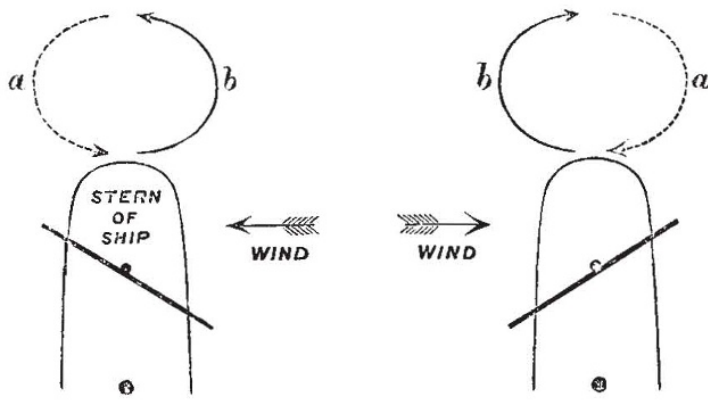

FIG. 3 .

when the wind is strong the sea is thrown into considerable waves, which may affect the horizontal movement of the wind in immediate contact with them. There certainly seems to be some connection between the way the wings are spread to the wind's direction, the sliding up and down in their sweeping circle (Fig. 3), and their method of flight.

David Wilson-Barker.

\section{The Locomotion of Arthropods.}

I HAVE been making some observations on the locomotion of various insects, and find that in the case of those which move quickly the best method for observation is instantaneous photography. Instantaneous photographs of moving flies show that they move the front and hind leg of one side almost simultaneously with the middle leg of the other, while they stand on the other three. When the tripod which is moving has come to the ground, the other tripod is raised, and so on. The photographs show, however, that while no leg of one tripod ever moves simultaneously with any leg of the other, yet there is a succession in the movements of the legs of each tripod. The hind leg on one side is first moved, then the middle on the other, and when the hind leg has been moved forward and almost reached the ground, the front leg of that side is raised. The middle leg and the front leg of the opposite sides come to the ground almost simultaneously. It is usually just when the hind leg is reaching the ground, and the front leg is being raised, that the tripod on which the fly is resting thrusts the body forward. After the movement of each tripod there appears to be a short pause, during which all six legs are on the ground together.

I have observed this "tripodic" walk in earwigs, water scorpions, aphides, and some beetles. In the case of some slowly moving beetles and aphides which can be observed without photographic means, quite irregular movements have been observed. By cooling aphides, they can be made to move very slowly. In this condition one was observed to move its legs in slow succession in the following order: (1) right hind, (2) right middle, (3) right front, (4) left hind, (5) left middle, (6) left front. This walk was continued for some time, occasionally interrupted by the following order, or some other quite irregular walk: (I) right hind, (2) right middle, (3) left hind, (4) left middle, (5) left front, (6) right front.

In caterpillars the legs forming a pair seem to move simultaneously ; the motion begins at the posterior end of the body, and proceeds regularly forward till the most anterior pair of legs are moved.

The above few observations, which were made in the Physical Laboratory of Trinity College last spring, formed the subject of a recent communication to the Dublin University Experimen. tal Association. I hope to be able to extend this application of photography to the other groups of Arthropoda.

Physical Laboratory, Trinity College, Dublin. H. H. Dixon.

P.S.-In taking the photographs a small camera with magnifying lens and fast shutter were used, and the analyses of the

NO. I IO5, YOL. 43 ] 